\title{
Flyover-Noise Reduction of Commercial Aircraft via Reduced Slat Deflections and Modified Flight Procedures
}

\author{
Bruce L. Storms ${ }^{1}$ James C. Ross ${ }^{2}$, and James C. Jensen ${ }^{3}$ \\ NASA Ames Research Center, Moffett Field, CA 94035, U.S.A.
}

\begin{abstract}
Current regulation and operation of commercial aircraft result in flyover noise that generates public protest well outside the recognized noise footprint of modern airports. This noise issue was recently exacerbated by the implementation of NextGen air-traffic control which uses GPS-based navigation for predictable flight paths and improved efficiency. This study documents flyover noise in residential communities during early approach (15-20 nautical miles from landing). Since airframe noise is significant during approach, reduced slat deflections are explored as a potential noise-reduction configuration. To document the aerodynamic effects of lower slat deflections, CFD simulations were conducted for an aircraft configuration representative of early approach. Additionally, modified flight procedures are proposed to mitigate existing flyover noise levels. Field measurements of flyover noise indicate a 5-8 dB difference between commercial aircraft with and without slats deployed. Both noise-mitigation strategies have promise, but reduced slatdeflection configurations will not likely be adopted without additional noise-certification requirements. Hence, the most promising near-term noise mitigation is to modify flight procedures to delay slat deployment and/or provide multiple approach flight paths.
\end{abstract}

\section{Nomenclature}

$\begin{array}{ll}C_{L} & =\text { lift coefficient } \\ C_{D} & =\text { drag coefficient } \\ d B & =\text { decibels } \\ d B A & =\text { decibels, A-weighted } \\ h & =\text { aircraft altitude, } \mathrm{ft} \\ k t s & =\text { knots or nautical miles per hour } \\ N M & =\text { nautical mile(s) } \\ O A S P L & =\text { overall sound pressure level } \\ U & =\text { aircraft flight speed, kts }\end{array}$

\section{Introduction}

The Next Generation Air Transportation System (NextGen) is a modernization of U.S. air-traffic control led by the Federal Aviation Administration (FAA). To make commercial transport safer, more efficient, and more predictable, NextGen implementation began in 2015. Since then, there has been a dramatic increase in flyover-noise complaints ranging from 15 to 75 times the number of complaints prior to NextGen implementation [1-3]. NextGen's GPS-based navigation has changed relatively random flight paths into predictable flight corridors as illustrated by the flight paths into Boston Logan Airport (Fig. 1) [1]. A side-effect of these narrow flight corridors is a perceived increase in noise level and annoyance experienced by the residents directly under the flight paths. The resulting nationwide protest is exemplified by the noise-complaint map near San Francisco International Airport (SFO) (Fig. 2) in which the vast majority of complaints are from residents 15-25 NM from the airport [2]. The community noise impact of NextGen has resulted in federal court decisions against the FAA [3] as well as legislation in the U.S. Congress [4]. To date, there has been no resolution in the increased noise levels due to the narrow NextGen flight corridors.

\footnotetext{
${ }^{1}$ Aerospace Engineer, Experimental Aero-Physics Branch.

${ }^{2}$ Aerospace Engineer, Experimental Aero-Physics Branch, Member AIAA.

${ }^{3}$ Aerospace Engineer, Computational Aerosciences Branch, Member AIAA.
} 
Aircraft noise standards in the United States are established by the FAA based on acoustic measurements of commercial aircraft near the airport. More specifically, there are three certification points (takeoff, landing, and sideline) all within two nautical miles of the airport runways [5]. Due to the proximity of these certification points, modern commercial aircraft are acoustically optimized for the takeoff and landing configurations. Additionally, the high-lift configurations and aircraft pitch angles at the acoustic certification points are significantly different than those of early approach (10-20 NM from the airport). Thus, the acoustic profile of commercial aircraft is essentially unregulated during early approach which is the source of the increased noise complaints.

Upon entering the terminal area some 15-20 NM from touchdown, engine noise is relatively low and the flow over the airframe is a significant noise source [6]. With the goal of maintaining adequate stall margin (i.e., safety), most commercial aircraft first deploy leading-edge slats while the flaps remain stowed (Fig. 3). Since modern highlift systems generally only have two slat settings (takeoff and landing), the first slat deflection in early approach is optimized for takeoff (relatively low speed and high angle of attack). In the off-design flight condition of early approach (high speed, low angle of attack), the slats can be a significant noise source. Slat noise was previously identified as a significant airframe noise source in a wind-tunnel study of a 26\%-scale Boeing 777-200 [7]. Similar to other experimental noise studies of commercial aircraft, this test focused on a high slat deflection (32 deg) which is typical of landing configurations. Additional wind-tunnel tests of a simplified wing configuration were conducted at multiple NASA Centers as well as at JAXA [8-10]. Of particular interest, acoustic spectra from a microphone array (Fig. 4) indicated that slat noise is a strong function of slat deflection with greatly reduced noise levels at lower slat angles [8]. More specifically, a reduction in slat deflection from 25- to 9-deg resulted in a 20-dB decrease in the peak noise level.

Based on these experimental results, the feasibility of lower slat deflections during early approach is explored as a possible solution to the community noise issue. To document the maximum potential noise reduction, field measurements were conducted on the ground at locations before, during, and after slat deployment. For safety considerations, the stall margin of a lower slat deflection was computed for a realistic geometry based on a modern commercial aircraft. In addition, modified flight procedures are addressed as another strategy for mitigating flyover noise from commercial aircraft. Current flyover noise metrics are also evaluated for their relevance to aircraft noise typical of early approach.

\section{Acoustic Field Measurements}

To investigate the aircraft overflight noise levels, acoustic measurements were made under the flight path at several locations ranging from 15-20 NM from landing at San Francisco International Airport. A sample of the Aweighted noise from an acoustic data logger is presented in Fig. 5 for an aircraft at an altitude of $6000 \mathrm{ft}$ and a distance of $20 \mathrm{NM}$ from the airport. The 30-minute plot contains the noise signatures of 10 overflights that are identified by the general shape and duration of a typical commercial aircraft flyover. The six-hour record highlights the significant frequency of flyover noise directly below the GPS flight corridor. The acoustic data logger recorded a background noise level near $45 \mathrm{~dB}$ with 72 events above $60 \mathrm{~dB}$ and 23 above $65 \mathrm{~dB}$. Higher noise levels were recorded further along the flight path where the aircraft descend over residents 10-20 NM from the airport.

The dynamic sound of slat deployment was also captured for numerous flyovers at the same location $20 \mathrm{NM}$ from landing. The A320 slat deployment, in particular, generates a rapid noise increase with a tonal quality that is significantly different than a flyover with slats already deployed. A comparison of two flyovers with and without slat deployment (Fig. 6) illustrates the dynamic quality of the event with an increase in the noise level of almost 20 $\mathrm{dB}$ in 3-4 seconds. In contrast, the flyover without slat deployment is characterized by a gradual increase followed by a gradual decrease from the maximum level when overhead. This dynamic noise event due to slat deployment is likely a significant contributor to the increase number of complaints under the narrow NextGen flight corridors.

Spectral measurements were also obtained at several points under the flight path during early approach. For these overflights, the aircraft wing configuration was determined by visual observation with binoculars. The aircraft type, ground speed, and altitude were also recorded from online resources. Since the measured acoustic levels are greatly influenced by flight speed and altitude, a correction developed by Fink [11] was applied to each flyover as shown in Eq. (1):

$$
\text { OASPL correction, } \mathrm{dB}=50 \log \left(\mathrm{U}_{\mathrm{o}} / \mathrm{U}\right)+20 \log \left(\mathrm{h} / \mathrm{h}_{\mathrm{o}}\right)
$$

where $U_{o}$ and $h_{o}$ are reference velocity and altitude for comparison (220 kts and $5000 \mathrm{ft}$, respectively). Data were excluded if exceeding recognized weather restrictions for flyover-noise measurements (wind speed $>12 \mathrm{kts}$, acceptable temperature, humidity, etc.) [12]. 
The difference between the averaged spectra for the Boeing 737 (Fig. 7) suggest that slat-related noise (including engine settings, exposed hardware, fuel vents, etc.) is broadband in the frequency range most important to human hearing $(1-5 \mathrm{kHz})$. The two spectra of this comparison are averages of multiple overflights: three clean-wing and two slats-deployed flyovers. Note that the tonal peaks evident in the clean-wing spectrum for frequencies above $2 \mathrm{kHz}$ were identified as electronic noise (not related to the aircraft). When these spectra were integrated, the Aweighted sound level increase due slat deployment was calculated as $8 \mathrm{~dB}$. This difference between slats-deployed and clean-wing noise levels represents the maximum potential noise reduction.

To further investigate commercial aircraft noise, a flyover data system was developed by integrating an acoustic data logger and an ADS-B receiver with a portable single-board computer (Fig. 8). ADS-B, or Automatic Dependent Surveillance-Broadcast, is a mandated surveillance technology in which aircraft broadcast their identification, position, and flight parameters for tracking purposes. This combination of logger and receiver enabled automated measurement of aircraft acoustics and flight details for long durations to provide a greater sample size for statistical analysis. When the distance between an aircraft and the flight data system was within a specified radius, the data system recorded both flyover acoustics and aircraft flight parameters. At several locations, it was possible to obtain both clean-wing and slats-deployed flyover-noise measurements for the same aircraft type due to variations in local traffic and specified approach speeds. In absence of visual observations, the wing configuration was inferred from the flight speed when above or below a speed range typical of slat deployment. For example, clean-wing and slats-deployed configurations were inferred from flight speeds above $250 \mathrm{kts}$ and below $220 \mathrm{kts}$, respectively, while flyovers between 220 and $250 \mathrm{kts}$ were excluded from the averages. The sound level of each overflight was adjusted for altitude and flight speed (as detailed above) and then averaged with overflights for the same wing configuration.

Compared with the 8-dB difference noted above for the B737 (from five flyovers with visual observation), the average of 84 flyovers yielded a difference in peak sound level of $5.2 \mathrm{~dB}$ between the slats-deployed and clean configurations. Similarly, flyovers of other common commercial aircraft were analyzed based on the expected slatdeployment speed for each aircraft. These average increments due to slat deployment (Table 1) are likely low estimates since visual observations indicate that slats are often deployed above $250 \mathrm{kts}$. Thus, the potential noise reduction from reduced slat deflections is likely closer to $8 \mathrm{~dB}$ as indicated above.

Table 1 Average increment in peak sound level after slat deployment.

\begin{tabular}{|c|c|c|}
\hline Aircraft & $\begin{array}{c}\text { No. of } \\
\text { flyovers }\end{array}$ & $\begin{array}{c}\text { Avg. slat-noise increment, dB } \\
\text { (slats deployed - clean wing) }\end{array}$ \\
\hline Airbus 320 & 28 & 6.0 \\
\hline Boeing 737 & 84 & 5.2 \\
\hline Boeing 777 & 24 & 4.9 \\
\hline Embraer 75L & 57 & 6.2 \\
\hline
\end{tabular}

\section{Reduced Slat Deflections}

As an aircraft enters the terminal area and descends below 10,000 ft, the FAA mandates a flight speed below 250 kts [13]. In addition, FAA requires that an aircraft's approach speed be at least 1.3 times the stall speed of its current wing configuration [14]. This mandated stall margin is ultimately what requires slat deployment during early approach. To minimize slat-related noise in early approach, it is suggested that a lower slat deflection (on the order of $10 \mathrm{deg}$ ) be added to the typical slat-deployment schedule as illustrated in Fig. 9. For reduced slat deflections to be a viable low-noise configuration, the lower slat deflections must be shown to provide adequate stall margins to meet the established safety requirements.

To investigate the aerodynamic effects of lower slat deflections, computational fluid dynamics (CFD) was used to simulate the flow over a Boeing 777-200 aircraft. This effort used existing grids that were originally generated for comparison with the $26 \%$-scale model tested in the 40 - by 80 -Ft Wind Tunnel in the late $1990 \mathrm{~s}$. This semi-span configuration included a multi-element wing with a flow-through nacelle, but only the landing configuration was studied experimentally [15]. The corresponding computations employed overset grid topology including approximately 20 million points. To validate the OVERFLOW solver, the landing configuration with full flaps and slats (37 and $32 \mathrm{deg}$, respectively) was computed for comparison with experimental data. Since the computations did not include tunnel walls, the resulting comparison (Fig. 10) shows the computed lift curve to be lower than that of experiment, as expected. However, the computed lift curve also exhibited a lower maximum lift and more abrupt 
stall than that of the experiment. These significant differences are likely due to discrepancies in the grid fidelity as noted by previous researchers [16].

Assuming that the general flow features are adequately captured by the computations, two additional high-lift configurations were simulated with nominal slat deflections of 11 and $22 \mathrm{deg}$, respectively. Since grids were not available for the clean trailing edge typical of early approach, both configurations include flap angles to approximate the aircraft's Flaps 20 setting. While not ideal, this configuration minimizes the effect of the flaps for the study of slat-deflection variation. The drag polars (Fig. 11) indicate that the maximum lift of the 11-deg slat deflection is reduced relative to that of the 22-deg deflection. Using the FAA requirement for approach speed, the increase in the associated minimum air speed is approximately $10 \mathrm{kts}$ (162 kts and $152 \mathrm{kts}$ for 11- and 22-deg slats, respectively). Since these computations include the Flaps 20 setting, they are not a true representation of the flow field in early approach (with slats only). However, this preliminary study suggests that the stall margins for reduced slat deflections fall within regulatory requirements. Due to the relatively high flight speeds of early approach (220-250 kts), it is expected that stall margins with reduced slat deflections will be adequate. To verify this, further CFD simulation is recommended for the slat-only configuration typical of early approach.

The logistics of setting lower slat angles on current aircraft were also investigated through discussions with FAA and aircraft manufacturers. The results suggest that modifying current aircraft would be prohibitively difficult due to existing control systems and hurdles in certification. For next-generation commercial aircraft, reduced slat deflections could be considered, but likely won't be developed if not mandated by FAA noise requirements during early approach. In the near term, other avenues for flyover noise reduction must be considered.

\section{Modified Flight Procedures}

Recognizing the barriers to reduced slat deflections on current commercial aircraft, modifications to operational flight procedures are suggested to reduce the community flyover noise in early approach. These flight procedures would necessarily be customized to each airport environment and admittedly may not be possible under all airtraffic scenarios. Using SFO as an example, several potential flight-procedure modifications are shown in Fig. 12 superimposed on a pre-NextGen noise-complaint map from 2014 [2]. These flight procedures are listed below in order of decreasing ease of application (based on the author's limited knowledge of air-traffic control):

\section{A. Delayed Slat Deployment}

This strategy would be the most effective since the slat noise would be limited to a smaller area closer to the airport. In the case of the northbound approach to SFO, the slat deployment for some aircraft can be delayed until over San Francisco Bay, thereby avoiding the additional slat noise during overflight of local communities. As documented by the field acoustic measurements presented earlier, this could provide a significant noise reduction ranging from 5-8 dB. However, delayed slat deployment corresponds to higher approach speeds which are only realistic during low-traffic operations. In addition, this strategy does not suit airports with large residential communities within $10 \mathrm{NM}$ of landing.

\section{B. Multiple GPS Flight Paths}

This approach would approximate the community noise prior to NextGen implementation by spreading the noise impact over a larger area and reducing the frequency of flyovers under the current narrow flight corridors. Admittedly, this would increase the airspace required for a given approach, but the flight paths would still be predictable and, thereby, provide equivalent safety. If assignment of aircraft to multiple approaches were automated, there would be little impact on the workload of the air-traffic controllers.

\section{Steeper Descent Profiles}

Since sound level varies with the inverse square of the distance from the source, this strategy has significant merit. To this end, glide slopes have already been increased from 3 to 3.2 deg at several European airports [17-18]. However, this marginal increase corresponds to a difference in altitude of about $320 \mathrm{ft}$ at $15 \mathrm{NM}$ from landing. By Eqn. (1) detailed earlier, the estimated difference in sound level at this location and altitude would be only $0.6 \mathrm{~dB}$. This minimal effect was confirmed by the current study's field measurements before and after changes to the northbound approach to SFO that resulted in marginally higher altitudes about 20 NM from landing. Steeper approaches up to $4.5 \mathrm{deg}$ have been studied at Frankfurt [19], but aircraft-performance and safety limitations have prevented widespread acceptance. In addition, steep descents required early deployment of relatively noisy flaps that negate much of the acoustic benefit of increased altitude. 


\section{Specified Slat-Deployment Locations}

By specifying approach flight speeds, air-traffic controllers have the ability to influence the location of slat deployment, preferably opting for unpopulated or high-noise areas. This strategy would mitigate the disruptive noise of slat deployment, but its implementation is challenging on many fronts. In particular, the numerous aircraft types do not have a uniform speed for slat deployment. Additionally, aircraft operators (i.e., the airlines) have company-specific operating procedures that are also nonuniform. These multiple variables make the specification of slat-deployment location unlikely as noise-reduction strategy.

In summary, delayed slat deployment and multiple flight paths have the most promise of the modified flight procedures listed above. Also, modified descent profiles will only have a measurable impact if approach glide paths are increased significantly. To quantify the effect of any flight-path change, noise metrics may also need to modified.

\section{Flyover Noise Metrics}

Currently, the Day Night Average Sound Level (DNL) is the U.S. federal metric for determining the cumulative impact on noise on residents surrounding airports [20]. The DNL is a 24-hr logarithmic average of the ambient sound level in decibels. In addition, DNL adds a $10-\mathrm{dB}$ noise penalty to each flyover occurring during nighttime hours from 10 p.m. to 7 a.m. This penalty is meant to compensate for the public's sensitivity during overnight hours and reportedly has a significant contribution to an airports noise profile. In addition, the FAA uses Sound Exposure Level (SEL) as a measure of the physical energy of a single noise event like an aircraft flyover.

Based on the Schultz curve, the FAA designated the $65-\mathrm{dB}$ contour as the noise exposure limit beyond which "residential land uses are not compatible". Outside the $65-\mathrm{dB}$ contour, it is left to local authorities to determine if a lower contour of noise exposure should be considered for mitigation measures. These measures, however, are assumed to be related to land use rather than influencing aircraft operations. At the residential location used for field measurements in this study (directly under the northbound approach to SFO and $20 \mathrm{NM}$ from landing), the typical DNL was $48-49 \mathrm{~dB}$. Since these levels are well below the recognized 65-dB contour, there is no legal motivation to change aircraft operations.

The significant increase in early-approach complaints suggest that the accepted noise metrics are inadequate for estimating the annoyance level of under NextGen flight paths. In addition to quantitative metrics like DNL and SEL, qualitative metrics need to be included to adequately represent the increased annoyance resulting from the GPS flight paths. Similar to the penalty for operations during nighttime hours, these new metrics could be included in quantitative metrics (e.g., DNL) to more accurately represent the impact on the local community. A few suggestions for annoyance metrics are included below:

\section{A. Tonal Content}

It is widely recognized that acoustic tones are much more annoying than broadband noise. This is also recognized in the FAA noise certification which penalizes aircraft noise spectra with significant tonal content [21]. However, due to the proximity of the certification points to the airport, this only affects the landing and takeoff configurations. Tones generated by aircraft during other phases of flight are not regulated even though higher speeds often correspond to much higher noise levels. The A320 aircraft, for example, is well known for a strong tone generate by fuel vents on the underside of the wings [22]. This tone is most noticeable at the high speeds and low angles typical of early approach, but the issue has endured for years since there is no regulation and, hence, no motivation for change. Only recently have some operators recognized the problem and invested in retrofit vortex generators that greatly reduce the noise exposure of local communities [23]

\section{B. Frequency of overflight}

Although the impact of multiple flyovers is captured quantitatively by the DNL metric, the qualitative annoyance due to many successive flyovers is not well represented. As discussed above, a DNL around $50 \mathrm{~dB}$ for a residential community does not warrant much attention from federal regulators, but the qualitative annoyance from 10 flyovers in 30 minutes (Fig. 5) has generated significant public protest. If a minimum period between flights were established (e.g., $5 \mathrm{~min}$ ), then methodology similar to that for nighttime flyovers could be devised to penalize multiple flyovers within the minimum period. Alternatively, the Noise and Number Index developed by previous researchers [24] could be incorporated as it was found to be a good prediction of annoyance response. 


\section{Dynamic Noise Events}

As discussed previously, some aircraft and flight conditions result in a rapid-rise noise signature when the slats are deployed. As illustrated in Fig. 6, the noise level can change as much as $20 \mathrm{~dB}$ in a few seconds. Repetitive noise events are disruptive and chronic exposure has been found to affect cognitive performance of students [25]. However, when analyzed quantitatively, both flyovers of Fig. 6 (with and without slat deployment) result in Sound Exposure Levels that differ by less than $1 \mathrm{~dB}$. As a result, the federally-accepted DNL metric does not account for the qualitative annoyance associated with dynamic events. This could easily be remedied by analysis software that recognizes the acoustic signature of slat deployment and adds a penalty.

\section{Conclusion}

Reduced slat deflections and modified flight procedures were explored as strategies to mitigate the impact of early-approach flyover noise on residential communities well outside the recognized $65-\mathrm{dB}$ airport noise contour. Acoustic field measurements under the flight paths of commercial aircraft indicate a potential noise reduction of 5-8 $\mathrm{dB}$ for reduced slat deflections. Computations of a representative Boeing-777 wing configuration indicate a marginal increase in stall speed for lower slat deflections which may be manageable at flight conditions typical of early approach. Since reduced slat deflections on existing aircraft are unlikely in the near term, potential low-noise flight procedures are discussed as a possibility to reduce the flyover noise during early approach. The most promising of these procedures are delayed slat deployment and multiple GPS flight paths. In addition, current aircraft noise metrics were found to be inadequate for capturing qualitative annoyances associated with frequent flyovers, dynamic noise events, and tonal content of aircraft noise. Lastly, current regulation of flyover noise at certification points near the airport do not mitigate aircraft flyover noise experience by a majority of neighboring residents. Hence, additional regulation is needed to spur innovation in aircraft design (e.g., reduced slat deflection) and minimize the impact of flyover noise on local residential communities.

\section{Acknowledgments}

This work was funded by NASA's Convergent Aeronautical Solutions program and the Center Innovation Fund. Contributions to field-data acquisition and analysis were made by Scott Christa, Tim Johnsen, David Keil, Hiro Kumagai, Hannah Spooner, and Bethany White.

\section{References}

[1] Woolhouse, M., "Officials will study plane noise after complaints about Logan," Boston Globe [online news], URL: https://www.bostonglobe.com/business/2016/10/07/faa-massport-agree-study-airplane-noise-afterrising-complaints/hIVSjqJnk5vwv6gAHzk0eI/story.html [7 October 2016].

[2] Santos, A., "New SFO flight paths causing record airplane noise complaints," Peninsula Press [online news], URL: http://peninsulapress.com/2015/11/23/sfo-airplane-noise-complaints/ [15 September 2016].

[3] Vogt, B., "FAA ordered to toss out Sky Harbor flight paths that raised noise levels," Cronkite News [online news], URL: https://cronkitenews.azpbs.org/2017/08/29/faa-ordered-to-toss-out-sky-harbor-flight-paths-thatraised-noise-levels/ [29 August 2017].

[4] "Airplane Noise Research and Mitigation Act of 2018," H.R.6454 - 115th Congress (2017-2018), https://www.congress.gov/bill/115th-congress/house-bill/6454, [19 July 2018].

[5] "Noise Levels for Transport Category and Jet Airplanes Under \$36.103," Code of Federal Regulations, FAA 14 CFR 36, Appendix B.

[6] Hubbard, H. (ed.), Aeroacoustics of Flight Vehicles: Theory and Practice, NASA Reference Publication 1258, Vol. 1, 1991, pp. 391-394.

[7] Horne, W. C.; Burnside, N. J.; Soderman, P. T.; Jaeger, S. M.; Reinero, B. R.; James, K. D.; and Arledge, T. K.: Aeroacoustic Study of a 26\%-Scale Semispan Model of a Boeing 777 in the NASA Ames 40- by 80-Foot Wind Tunnel. NASA/TP-2004-212802, Oct. 2004.

[8] Storms, B. L., Hayes, J. A., Moriarty, P. J., and Ross, J. C., "Aeroacoustic Measurements of Slat Noise on a Three-Dimensional High-Lift System," AIAA Paper 99-1957, May 1999.

[9] Lockard, D., and Choudhari, M., "Noise Radiation from a Leading-Edge Slat", AIAA 2009-3101, May 2009.

[10] Murayama, M., Nakakita, K., Yamamoto, K., Ura, H., Ito, Y., and Choudhari, M., "Experimental Study of Slat Noise from 30P30N Three-Element High-Lift Airfoil in JAXA Kevlar-Wall Low-Speed Wind Tunnel", AIAA Paper 2014-2080, June 2014.

[11] Fink, M., Airframe Noise Prediction Method, FAA-RD-77-29, Mar 1977. 
[12] Hubbard, H. (ed.), Aeroacoustics of Flight Vehicles: Theory and Practice, NASA Reference Publication 1258, Vol. 2, 1991, pp. 357-364.

[13] “Aircraft Speed," Code of Federal Regulations, FAA 14 CFR 91.117.

[14] "Reference Landing Approach Speed," Code of Federal Regulations, FAA 14 CFR 23.73.

[15] Storms, B.L., James, K. D., Satran, D. R., Arledge T. K., Burnside, N. J., Horne, W. C., and Driver, D. M., " Aerodynamics of a 26\%-Scale Semi-Span Model of the Boeing 777 in the NASA Ames 40- by 80- Foot Wind Tunnel", NASA TP-2005-212829, January 2005.

[16] Rogers, S., Roth, K., Cao, H., Slotnick, J., Whitlock, M., Nash, S., and Baker, M., "Computation of Viscous Flow for a Boeing 777 Aircraft in Landing Configuration", AIAA 2000-4221, August 2000.

[17] Glanfield, E., "Heathrow's new angle to win over neighbours: Planes to use a steeper landing as they descend in bid to cut noise levels," Daily Mail [online news], URL: https://www.dailymail.co.uk/news/article3193195/Heathrow-s-new-angle-win-neighbours-Planes-use-steeper-landing-descend-bid-cut-noiselevels.html [11 August 2015].

[18] Belamy, W., "DFS Sees GBAS as Future Precision Landing System," Aviation Today [online news], URL: https://www.aviationtoday.com/2017/04/14/dfs-sees-gbas-future-precision-landing-system/ [14 April 2017].

[19] "Tests at Frankfurt airport of steeper approach path at 4.5 degrees - details awaited," Airport Watch [online news], URL: http://www.airportwatch.org.uk/2013/10/tests-at-frankfurt-airport-of-steeper-approach-path-at-45-degrees-details-awaited/ [11 October 2011].

[20] "Day Night Average Sound Level (DNL)," Environmental Desk Reference for Environmental Actions, FAA Office of Airports, Chapter 17, pg. 1, October 2007.

[21] "Calculation of Effective Perceived Noise Level from Measured Data," Code of Federal Regulations, FAA 14 CFR 36, Appendix A, Section A36.4.

[22] "Airframe noise from the A320 aircraft family" Airport Watch [online news], URL: http://www.airportwatch.org.uk/2014/11/lufthansa-retrofitting-a320-family-with-simple-inexpensive-noisereducing-device-to-stop-the-airbus-whine/ [16 October 2013].

[23] Vega, P., "In wake of noise complaints from Huntington Beach, JetBlue announces plans to retrofit jets to make them quieter," Los Angeles Times [online news], URL: https://www.latimes.com/local/lanow/la-me-lnjet-blue-huntington-beach-20181012-story.html [12 October 2018].

[24] Powell, C. A.: Multiple-Event Airplane Noise Annoyance, NASA/TP-2101, Jan. 1983.

[25] Haines, M., Stansfeld, S., Job, R. and Berglund, B., "Chronic aircraft noise exposure, stress responses, mental health and cognitive performance in school children", Psychological Medicine, Vol. 21, Issue 2, February 2001, pp. 265-277.

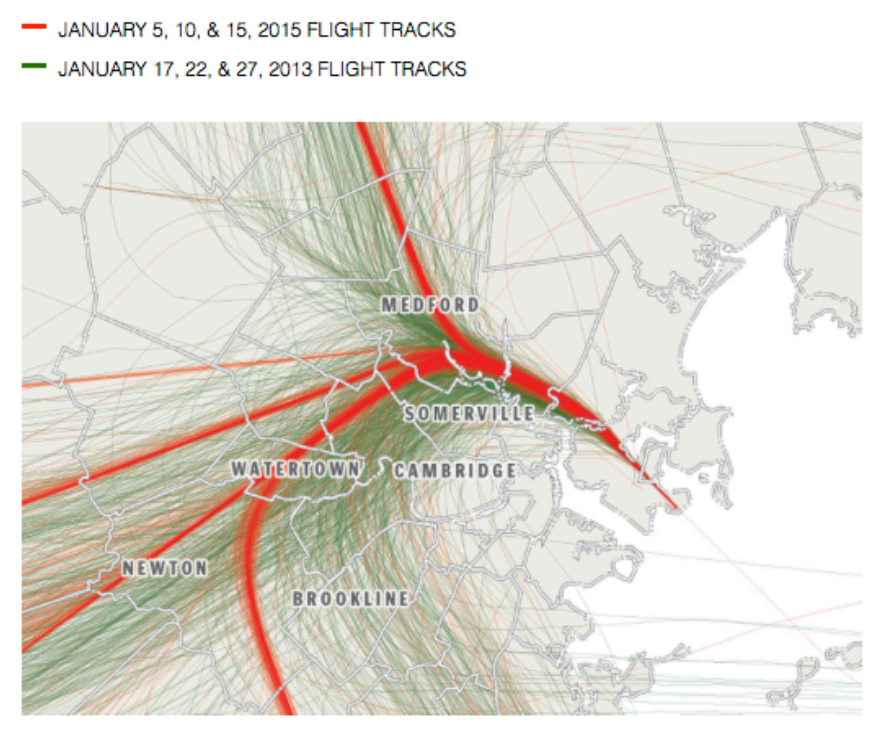

Fig. 1 NextGen's narrow flight corridors (orange) into Boston Logan Airport; green traces are flight paths prior to NextGen implementation [1]. 


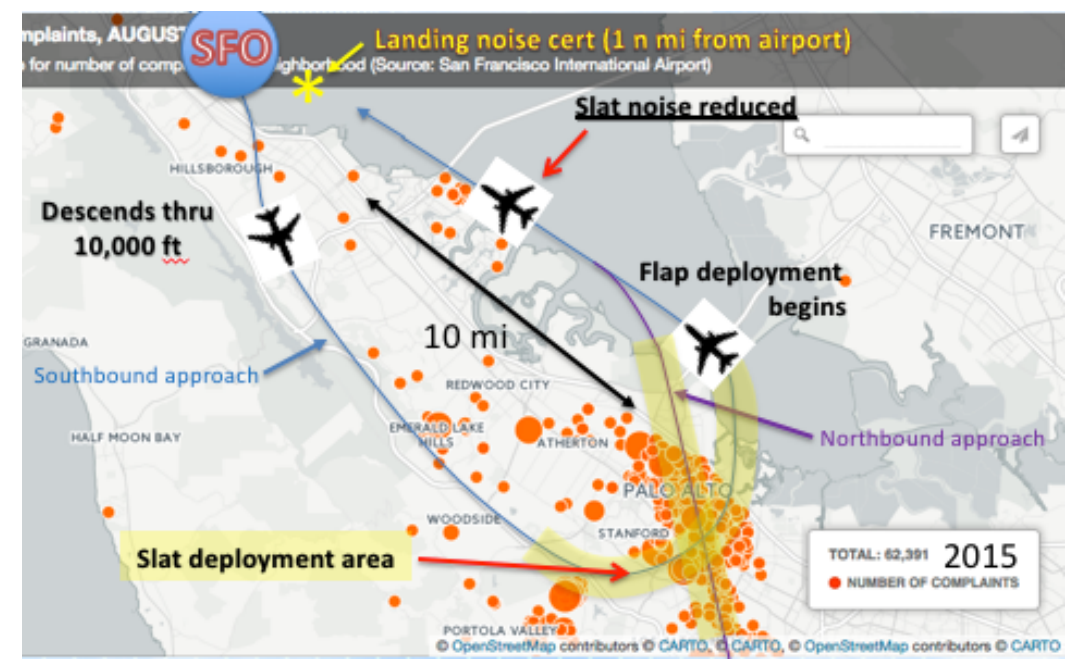

Fig. 2 Typical north- and southbound approach to SFO superimposed on a noise-complaint map [2].

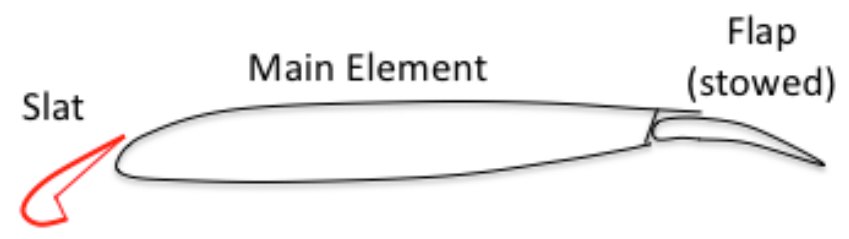

Fig. 3 Slat-only wing configuration typical of commercial aircraft during early approach to landing.

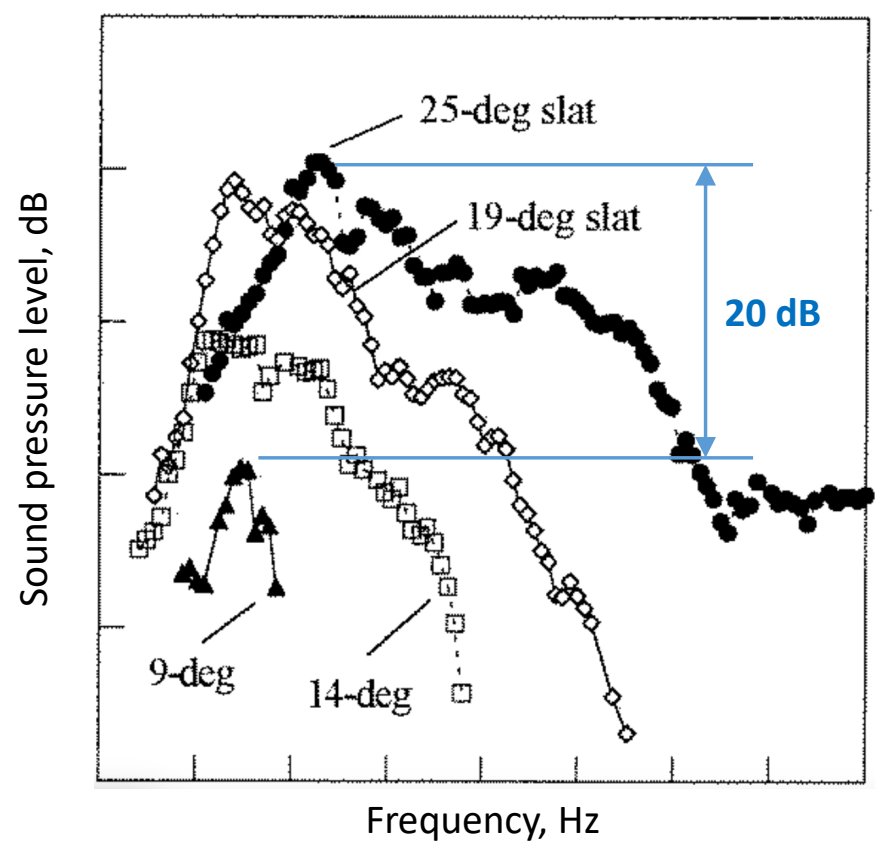

Fig. 4 Acoustic spectra from Ref. [8] illustrating the noise-reduction potential of reduced slat deflections. 

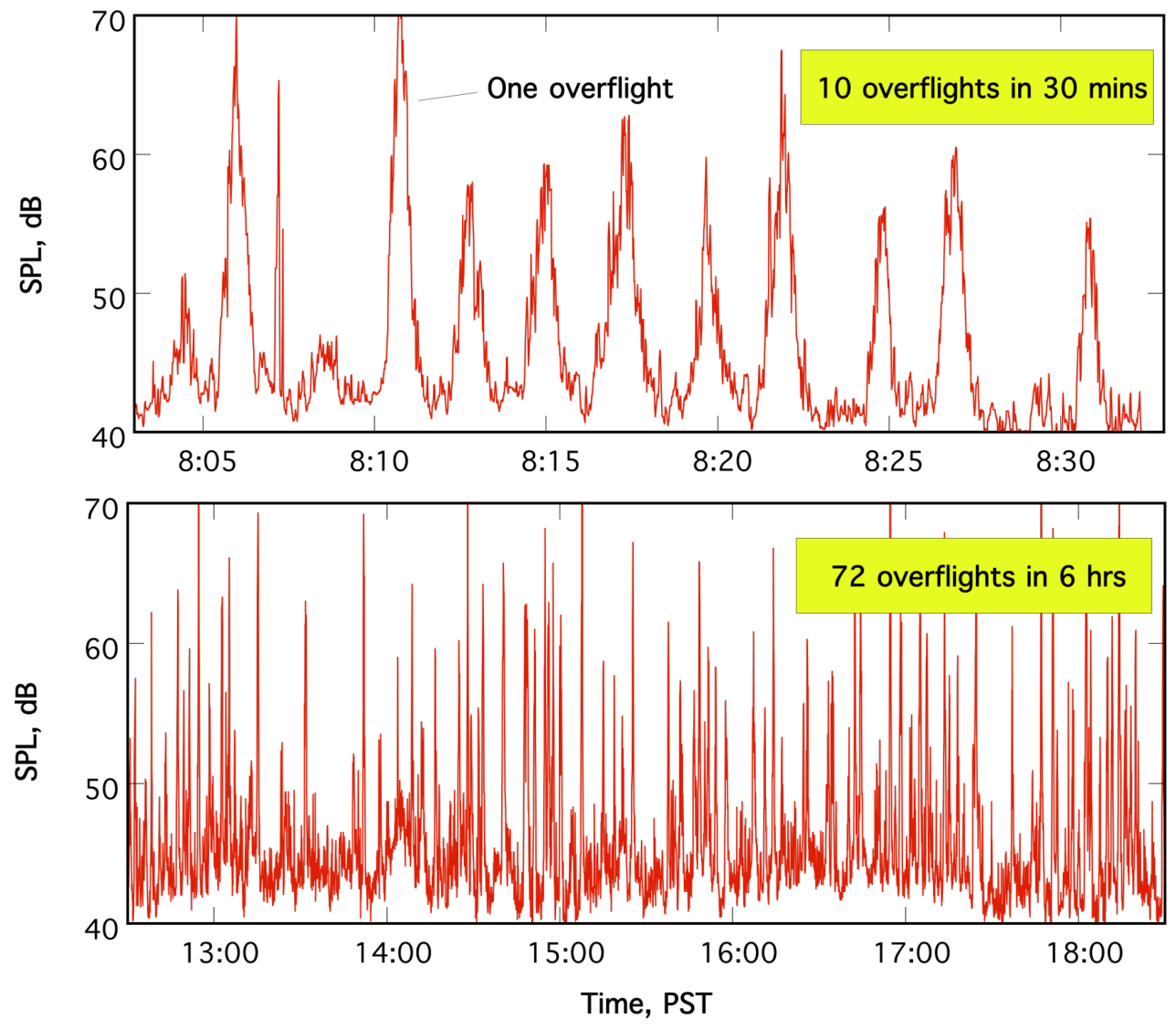

Fig. 5 A-weighted sound pressure levels recorded under the flight path $20 \mathrm{NM}$ from the airport.

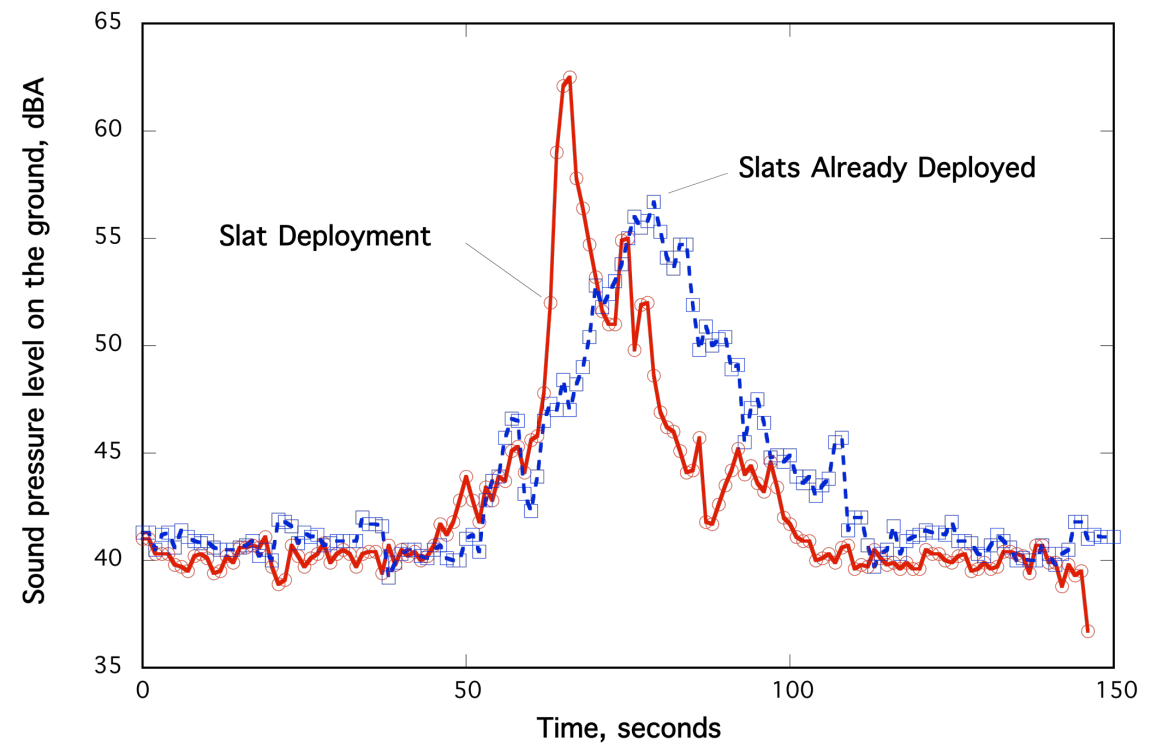

Fig. 6 Sound pressure levels on the ground from A320 flyovers with and without slat deployment. 


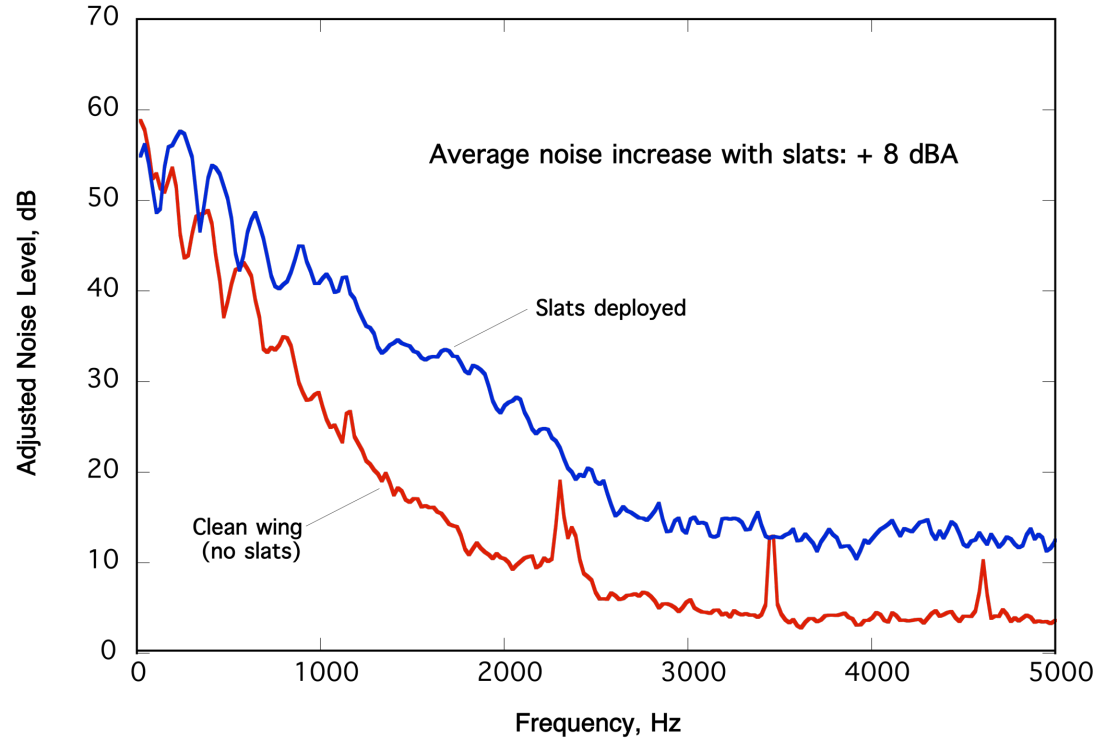

Fig. 7 Noise spectra for Boeing 737 with and without slats deployed (adjusted for altitude and speed).

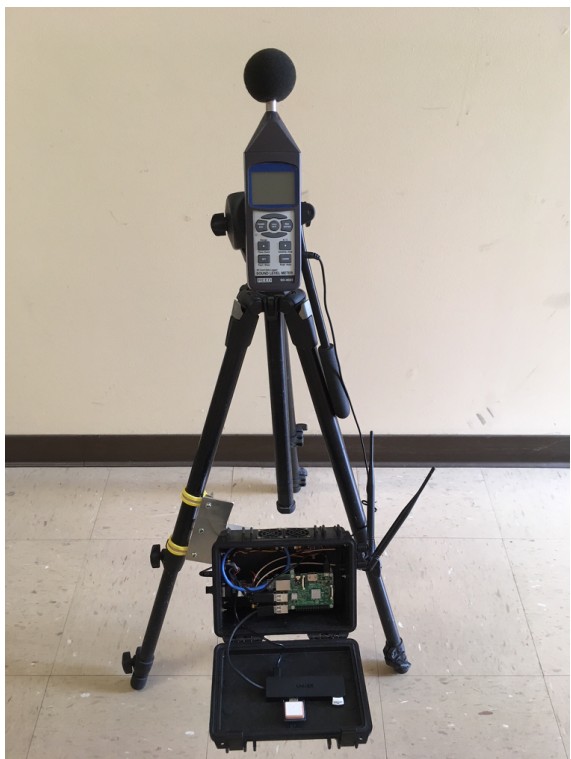

Fig. 8 Flight data system incorporating an acoustic data logger (top) and ADS-B receiver (bottom) for automated data acquisition.

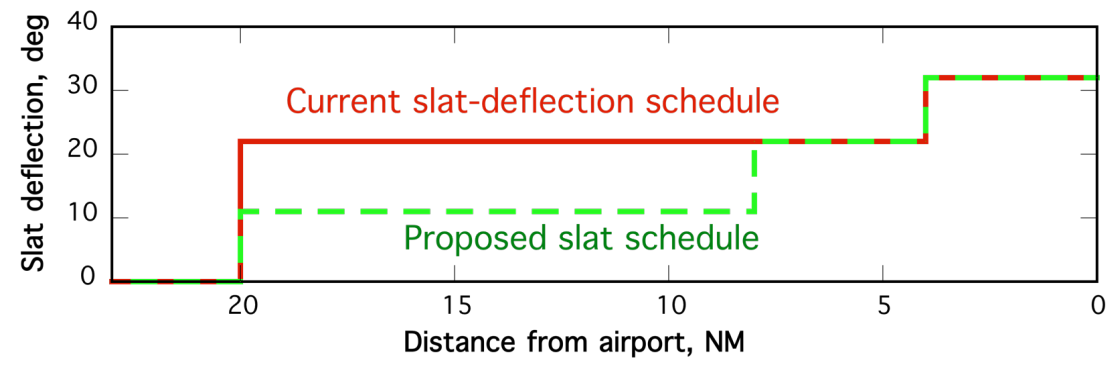

Fig. 9 Proposed reduction in slat deflection during early approach to landing. 


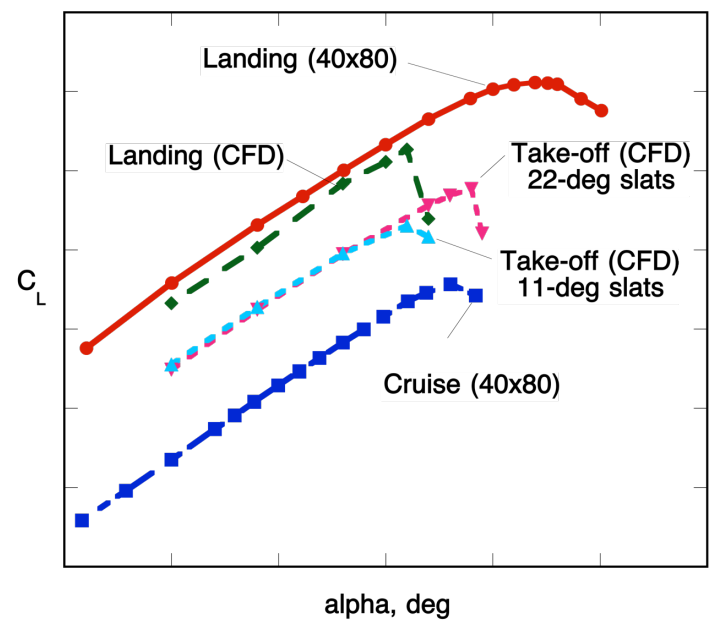

Fig. 10 Experimental and computed lift curves for the $26 \%$-scale model of a Boeing 777-200.

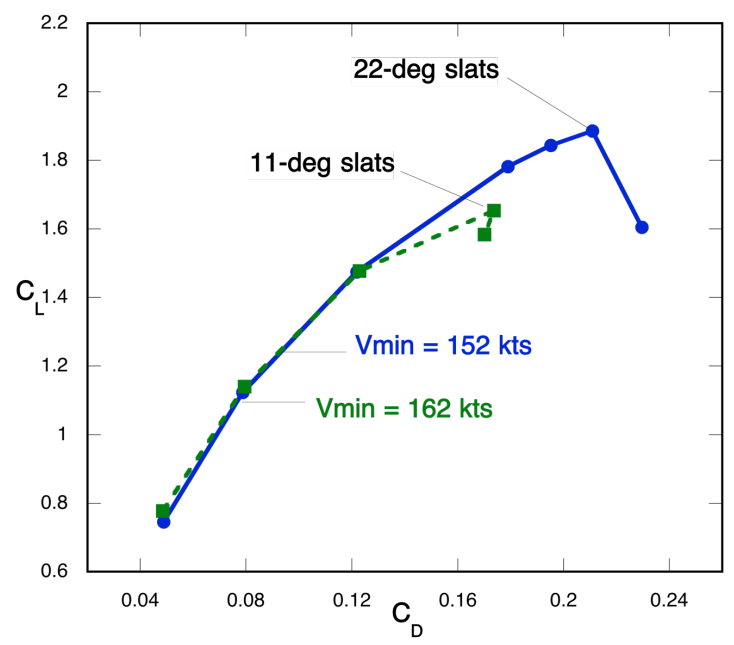

Fig. 11 Computed drag polars for slat deflections of 11 and $22 \mathrm{deg}$ (Flaps 20).

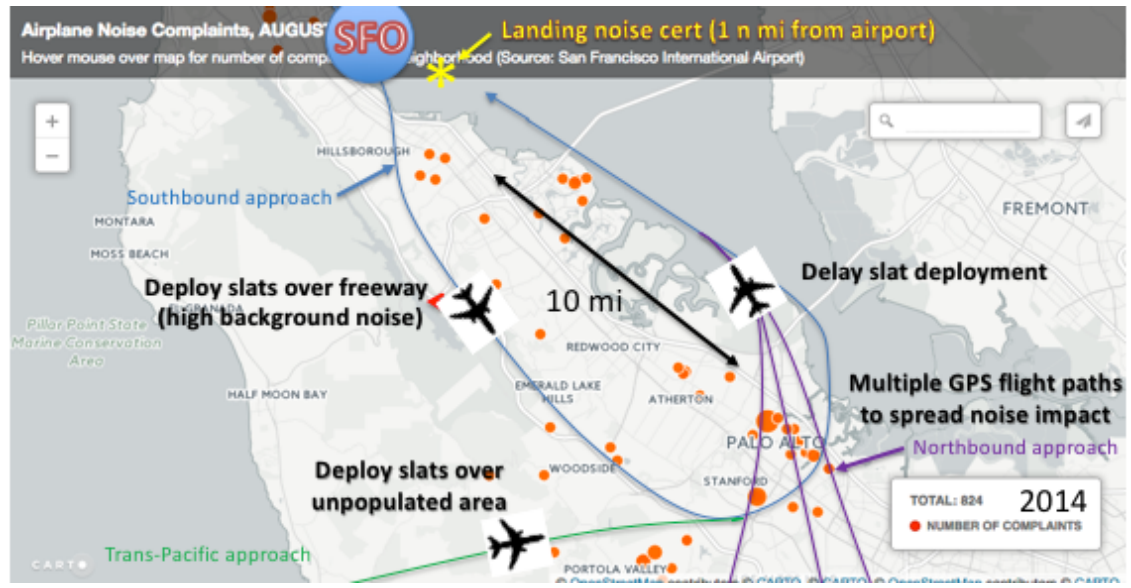

Fig. 12 Low-noise flight procedures to avoid slat-related noise during early approach (superimposed on a noise-complaint map prior to NextGen implementation [2]). 